Brazilian Journal
of Chemical
Engineering

\title{
INVESTIGATION OF HYDRODYNAMICS AND HEAT TRANSFER IN PSEUDO 2D SPOUTED BEDS WITH AND WITHOUT DRAFT PLATES
}

\author{
S. H.Hosseini ${ }^{1}$, M.Fattahi ${ }^{2}$ and G. Ahmadi ${ }^{3}$ \\ ${ }^{1}$ Department of Chemical Engineering, Ilam University, Ilam 69315-516, Iran \\ ${ }^{2}$ Department of Chemical Engineering, Faculty of Engineering, University of Kurdistan, Sanandaj 66177, Iran \\ ${ }^{3}$ Department of Mechanical and Aeronautical Engineering, Clarkson University, Potsdam, NY 13699-5725, USA \\ *Corresponding author: E-mail s.h.hosseini@ilam.ac.ir; Tel: +98 9137944470
}

(Submitted: September 15, 2015; Revised: May 21, 2016; Accepted: June 12, 2016)

\begin{abstract}
In the present study, hydrodynamics and gas to particle heat transfer in pseudo two dimensional spouted beds (2DSB) with and without draft plates were investigated using the Eulerian-Eulerian approach. The main objective of the study was to provide an understanding of effects of the presence of draft plates on the hydrodynamics and heat transfer behavior of solid particles in the spouted beds. To validate the model, the predicted mean particle vertical velocity at the bed axis, the lateral profiles of vertical particle velocity at different bed heights for both systems, and the particle velocity vector fields in the beds were compared with the experimental measurements. A close agreement between the CFD results and the experimental data was found for both systems. The simulation results showed that the particle volume fraction in the spout and fountain regions of the spouted bed with draft plates is considerably lower than that in a conventional spouted bed (without draft plates). Simulation results also showed significant differences between the temperature distributions of gas and solid phases in spouted beds with and without draft plates.
\end{abstract}

Keywords: Spouted bed, CFD, Hydrodynamic, Heat transfer, Draft plates.

\section{INTRODUCTION}

The original spouted bed was developed in 1954 as an alternative method of drying for a badly slugging fluidized bed of moist wheat particles. Because of the vigorous particle circulation, much hotter air than in conventional wheat driers could thus be used without damaging the grain. Realizing that the technique could have wider application, the NRC group studied the characteristics of spouted beds for a variety of solid materials, with both air and water as spouting media. On the basis of this preliminary study, they asserted that the mechanism of flow of solids as well as of gas in this technique is different from fluidization, but it appears to achieve the same purpose for coarse particles as fluidization does for fine materials.
A spouted bed typically displays three distinct regions: a central spout, annulus or downcomer, and a fountain region (Epstein and Grace, 2011).Therefore, hydrodynamics, heat transfer and mass transfer behaviours of spouted beds are quite different from fluidized beds and due to high circulation and stable behavior of particles, spouted beds have high performance.

By increasing computational power, the recent advances in numerical algorithms, and deeper understanding of multiphase flow processes, computational fluid dynamics (CFD) modeling has emergedas a powerful tool for predicting behaviour of each phase of multiphase flows. Among the different approaches for modeling the multiphase flows, the Eulerian-Eulerian approach, in which both phases are treated as interpenetrating continua

\footnotetext{
* To whom correspondence should be addressed
} 
(Deen et al., 2007; Szafran and Kmiec, 2004; Duarte et al., 2005), is used in the present study.

Thin rectangular spouted beds (pseudo two-dimensional spouted beds) have been used extensively in the literature since it models a simpler seeming two-dimensional flow configuration for experimental and computational study. In particular for experimental study, the thin rectangular spouted bed setup allows for optical access for direct measurement of the fluid dynamics. Some researchers investigated the hydrodynamic behaviour of two dimensional spouted beds (2DSB) with and without draft plates (Kalwar et al., 1993; Zhao et al., 2008a; Hosseini et al., 2009; Shuyan et al., 2010; Azizi et al., 2010; Moradi et al., 2013). It is worth mentioning that, for overcoming many complexities involving operation and control of conventional spouted beds, draft tubes are inserted into these beds.

Hosseini et al. (2010) used an Eulerian-Eulerian twofluid model of MFIX code for studying the hydrodynamics of 2DSB without draft plates. They reported that the CFD model is sensitive to the modelling parameters such as restitution coefficient, drag function, and frictional stresses. Zhao et al. (2008b) simulated the hydrodynamics of a 2DSB without draft plates using the DEM technique.

Zhao et al. (2008a) investigated theflow pattern of particles in a 2DSB with draft plates by both PIV measurement and DEM-CFD simulation considering the turbulence effect.They found that entrainment height has little effect on the particle vertical velocity, while it does exert a great effect on the solid circulation rate of the particles. Shuyan et al. (2010) studied the hydrodynamics of 2DSB with draft plates by Eulerian-Eulerian approach. Their results revealed that the impact of the frictionalkinetic closure of solid phase on the flow behaviour is significant. Moradi et al. (2013) studied the hydrodynamics of 2DSB with draft plates by TFM approach and compared their results with experimental measurements of Zhao et al. (2008a). They showed that, by increasing distance between plates and entrainment height, the rate of particle circulationincreases.

It is interesting to note that almost all the CFD simulations of pseudo 2D gas-solids fluidized beds usually predict poor quantitative agreement with the experimental data. More recently, Hosseini et al. (2015) in their simulation of a thin rectangular spouted bed showed that a $2 \mathrm{D}$ simulation is not adequate for predicting the experimental data as the effectsof front and back walls become quite important. Therefore, in the present study bed thickness has been considered for simulation of 2DSBs with and without draft plates.

Due to the complexity of the gas-solid systems, few studies related to the heat transfer of these systems have been reported in the literature(Brown and Lattimer, 2013; Hamzehei et al. 2010).Recently, Sutkar et al.
(2016) performed CFD-DEM simulations and also an experimental study ofheat and mass transfer in a pseudo2D spout fluidized bed with liquid injection. A combination of particle image velocimetry (PIV) and infrared thermography (IRT) were used in their experimental investigation. In the most common applications of spouted beds, however,heat transfer plays an important role. These includes drying (Kmiec et al., 1982; Rosiane et al., 2000), coating (Kucharski and Kmiec, 1983; Kucharski, 1989; Kmiec and Jabarin, 2000; and Filho et al., 2006) and chemical reaction applications such as pyrolysis and gasification of solid wastes (Olazar et al., 2000; Aguado et al., 2002; Arabiourrutia et al., 2007; Elordi et al., 2009; Lopez et al., 2010; Makibar et al., 2011; Lopez et al., 2013). Thus, knowledge of heat transfer and the temperature distribution across the spouted beds is critical to the designand operation of these systems. In the present study, hydrodynamics and gas to particle heat transfer in 2DSB with and without draft plates are studied using the Eulerian-Eulerian computational approach.

\section{NUMERICAL SOLUTION}

\section{Equations}

The equations used to perform CFD simulations of hydrodynamics and gas-solid heat transfer in 2DSB with and without draft plates are presented in this section. All models used in simulation of 2DSB with and without draft plates except the frictional pressure model of solids are the same.It should be pointed out that Shuyan et al. (2010) investigated the effect of frictional pressure model of solid phase on the CFD results of a 2DSB with a draft tube and showed that the CFD model including the Johnson and Jackson (1987) expression predicts reasonable results. Accordingly, in this research, the Johnson and Jackson (1987) model is used for the frictional pressure model of solid phasein the case of 2DSB with draft plates and the model based on kinetic theory of granular flows is used in the case of 2DSB without draft plates. The governing equations for the spouted bedsarelisted in this section:

\section{Governing equations}

The continuity equation for the $q^{\text {th }}$ phase without any mass transfer between the phases is given by:

$$
\frac{\partial}{\partial t}\left(\alpha_{q} \rho_{q}\right)+\nabla \cdot\left(\alpha_{q} \rho_{q} \vec{v}_{q}\right)=0
$$

where $\alpha_{q}, \rho_{q}$ and $\vec{v}_{q}$, respectively, are the volume fraction, density and velocity of the $q^{\text {th }}$ phase. The conservation of momentum for the gas and solid phases is given as: 
The conservation of momentum for the gas and solid phases is given as:

Gas phase:

$$
\frac{\partial}{\partial t}\left(\alpha_{g} \rho_{g} \vec{v}_{g}\right)+\nabla \cdot\left(\alpha_{g} \rho_{g} \vec{v}_{g} \vec{v}_{g}\right)=-\alpha_{g} \nabla p+\nabla \cdot \overline{\bar{\tau}}_{g}+\beta\left(\vec{v}_{s}-\vec{v}_{g}\right)+\alpha_{g} \rho_{g} g
$$

Solida phase:

$$
\frac{\partial}{\partial t}\left(\alpha_{s} \rho_{s} \vec{v}_{s}\right)+\nabla \cdot\left(\alpha_{s} \rho_{s} \vec{v}_{s} \vec{v}_{s}\right)=-\alpha_{s} \nabla p-\nabla p_{s}+\nabla \cdot \overline{\bar{\tau}}_{s}+\beta\left(\vec{v}_{g}-\vec{v}_{s}\right)+\alpha_{s} \rho_{s} g
$$

where $\alpha_{s}=1-\alpha_{g}$.

The conservation of energy for the gas and solid phases is given as:

Gas phase:

$$
\frac{\partial}{\partial t}\left(\alpha_{g} \rho_{g} H_{g}\right)+\nabla \cdot\left(\alpha_{g} \rho_{g} \vec{v}_{g} H_{g}\right)=\nabla \cdot \alpha_{g} K_{g, e f f} \nabla \cdot T_{g}-h_{g s}\left(T_{s}-T_{g}\right)
$$

Solid phase:

$$
\frac{\partial}{\partial t}\left(\alpha_{s} \rho_{s} H_{s}\right)+\nabla \cdot\left(\alpha_{s} \rho_{s} \vec{v}_{s} H_{S}\right)=\nabla \cdot \alpha_{s} K_{s, e f f} \nabla \cdot T_{s}+h_{s g}\left(T_{s}-T_{g}\right)
$$

The transport equation for granular temperature, $\Theta_{s}$ (fluctuation kinetic energy of particles), is given as:

$$
\frac{3}{2}\left[\frac{\partial}{\partial t}\left(\rho_{s} \alpha_{s} \Theta_{s}\right)+\nabla \cdot\left(\alpha_{s} \rho_{s} \vec{v}_{s} \Theta_{s}\right)\right]=\left(-\nabla p_{s} \bar{I}+\overline{\bar{\tau}}_{g}\right): \nabla \vec{v}_{s}+\nabla \cdot\left(k_{s} \nabla \Theta_{s}\right)-\gamma_{s}-3 \beta \Theta_{s}
$$

\begin{tabular}{|c|c|}
\hline \multicolumn{2}{|l|}{ 1. Solid and gas phase stress tensors } \\
\hline$\overline{\bar{\tau}}_{g}=\alpha_{g} \mu_{g}\left\{\left[\nabla \vec{v}_{g}+\left(\nabla \vec{v}_{g}\right)^{T}\right]-\frac{2}{3} \nabla \vec{v}_{g} \vec{I}\right\}$ & $(\mathrm{T} 1-1)$ \\
\hline$\overline{\bar{\tau}}_{s}=\alpha_{s} \mu_{s}\left[\nabla \vec{v}_{s}+\left(\nabla \vec{v}_{s}\right)^{T}\right]+\left(\alpha_{s} \lambda_{s}-\frac{2}{3} \alpha_{s} \mu_{s}\right) \nabla \cdot \vec{v}_{s} \bar{I}$ & $(\mathrm{~T} 1-2)$ \\
\hline $\begin{array}{l}\text { 2. Solid pressure (Lun et al., 1984) } \\
P_{s}=\alpha_{s} \rho_{s} \Theta_{s}+2 \rho_{s}\left(1+e_{s}\right) \alpha_{s}^{2} g_{0} \Theta_{s}\end{array}$ & $(\mathrm{~T} 1-3)$ \\
\hline \multicolumn{2}{|c|}{ 3. Frictional solid pressure (Johnson and Jackson, 1987) } \\
\hline$P_{s, f}=F \frac{\left(\alpha_{s}-\alpha_{s, \min }\right)^{n}}{\left(\alpha_{s, \max }-\alpha_{s}\right)^{n}}$ & $(\mathrm{~T} 1-4)$ \\
\hline \multicolumn{2}{|l|}{ 4. Solid shear viscosity } \\
\hline$\mu_{s}=\mu_{s, c o l}+\mu_{s, k i n}+\mu_{s, f r}$ & $(\mathrm{~T} 1-5)$ \\
\hline \multicolumn{2}{|c|}{ 5. Collisional viscosity (Gidaspow et al., 1992) } \\
\hline$\mu_{s, c o l}=\frac{4}{5} \alpha_{s} \rho_{s} d_{s} g_{0}\left(I+e_{s s}\right)\left(\frac{\Theta_{s}}{\pi}\right)^{\frac{1}{2}}$ & $(\mathrm{~T} 1-6)$ \\
\hline \multicolumn{2}{|l|}{ 6. Kinetic viscosity(Gidaspow et al., 1992) } \\
\hline$\mu_{s, k i n}=\frac{10 d_{s} \rho_{s} \sqrt{\pi \Theta_{s}}}{96\left(1+e_{s}\right) g_{0}}\left[1+\frac{4}{5} \alpha_{s} g_{0}\left(1+e_{s}\right)\right]^{2}$ & $(\mathrm{~T} 1-7)$ \\
\hline \multicolumn{2}{|l|}{ 7. Frictional viscosity(Schaeffer, 1987) } \\
\hline$\mu_{s, f r}=\frac{P_{S} \sin \phi}{2 \sqrt{I_{2 D}}}$ & $(\mathrm{~T} 1-8)$ \\
\hline \multicolumn{2}{|l|}{ 8. Solid bulk viscosity (Lun et al., 1984) } \\
\hline$\lambda=\frac{4}{3} \alpha_{s} \rho_{s} d_{s} g_{0}\left(1+e_{s}\right) \sqrt{\frac{\Theta_{s}}{\pi}}$ & (T1-9) \\
\hline
\end{tabular}

The corresponding constitutive equations for analyzing the spouted beds are listed in Table 1 .

Table 1. Constitutive equations used in the present simulations. 
Table 1. Cont.

9. Diffusion coefficient of granular energy (Gidaspow et al., 1992)

$k_{\Theta_{s}}=\frac{150 \rho_{s} d_{s} \sqrt{\pi \Theta_{s}}}{384\left(1+e_{s}\right) g_{0}}\left[1+\frac{6}{5} \alpha_{s} g_{0}\left(1+e_{s}\right)\right]^{2}+$

$+2 \alpha_{s} \rho_{s} d_{s} g_{0}\left(1+e_{s}\right)\left(\frac{\Theta_{s}}{\pi}\right)^{\frac{1}{2}}$

10. Collisional energy dissipation (Lun et al., 1984)

$\gamma_{s}=\frac{12\left(1-e_{s}^{2}\right) g_{0}}{d_{s} \sqrt{\pi}} \rho_{s} \alpha_{s}^{2} \Theta_{s}^{3 / 2}$

11. Radial distribution function (Ogawa et al., 1980)

$g_{0}=\left[1-\left(\frac{\alpha_{s}}{\alpha_{s, \max }}\right)^{1 / 3}\right]^{-1}$

12. Gas-solid drag coefficient (Huilin et al., 2003)

$\beta=\left(1-\varphi_{g s}\right) \beta_{E r g u n}+\varphi_{g s} \beta_{W e n-Y u}$ where

$\beta_{\text {Ergun }}=150 \frac{\alpha_{s}^{2} \mu_{g}}{\alpha_{g} d_{s}^{2}}+1.75 \frac{\alpha_{s} \rho_{g}\left|\vec{v}_{s}-\vec{v}_{g}\right|}{d_{s}}$ for $\alpha_{g} \leq 0.8$

$\beta_{W e n-Y u}=\frac{3}{4} C_{D} \frac{\alpha_{s} \alpha_{g} \rho_{g}\left|\vec{v}_{s}-\vec{v}_{g}\right|}{d_{s}} \alpha_{g}^{-2.65} \quad$ for $\quad \alpha_{g}>0.8$

$C_{D}=\left\{\begin{array}{c}\frac{24}{\alpha_{g} \operatorname{Re}}\left[1+0.15\left(\alpha_{g} \operatorname{Re}_{s}\right)^{0.687}\right], \\ 0.44, \operatorname{Re}_{s} \geq 1000\end{array} \quad \operatorname{Re}_{s}<1000 \quad\right.$ in which, $R e_{s}$

$R e_{s}=\frac{\rho_{g}\left|\vec{v}_{s}-\vec{v}_{g}\right| d_{s}}{\mu_{g}}$

$\varphi_{g s}=\frac{\operatorname{Arctan}\left[150 \times 1.75\left(0.2-\alpha_{s}\right)\right]}{\pi}+0.5$

13. Gas-solid heat transfer coefficient (Gunn, 1978)

$h_{s g}=\frac{6 k_{g} \alpha_{s} \alpha_{g} N u_{s}}{d_{s}^{2}}$

$N u_{s}=\left(7-10 \alpha_{g}+5 \alpha_{g}^{2}\right)\left(1+0.7 \operatorname{Re}_{p}^{0.2} P r^{\frac{1}{3}}\right)+$

$+\left(1.33-2.4 \alpha_{g}+1.2 \alpha_{g}^{2}\right) \operatorname{Re}_{p}{ }^{0.7} \operatorname{Pr}^{\frac{1}{3}}$

where $\operatorname{Pr}=\frac{C_{p g} \mu_{g}}{k_{g}}$ and $R e_{p}=\frac{\alpha_{g} \rho_{g} / \vec{v}_{s}-\overrightarrow{v_{g}} / d_{s}}{\mu_{g}}$

14. Effective thermal conductivity for gas and solid phases (Patil et al., 2006)

$K_{g, e f f}=\left(\frac{1-\sqrt{\alpha_{s}}}{\alpha_{g}}\right) K_{g} ; K_{s, e f f}=\frac{1}{\sqrt{\alpha_{s}}} k_{g}[\omega A+(1-\omega) \Gamma]$

where, $\quad \Gamma=\frac{2}{\left(1-\frac{B}{A}\right)}\left[\frac{(A-1)}{\left(1-\frac{B}{A}\right)^{2}} \frac{B}{A} \ln \left(\frac{A}{B}\right)-\frac{(B-1)}{\left(1-\frac{B}{A}\right)}-\frac{(B+1)}{2}\right] ; \quad A=\frac{K_{S}}{K_{g}} ; B=1.25\left(\frac{\alpha_{S}}{\alpha_{g}}\right)^{10 / 9} ; \omega=$

$7.26 \times 10^{-3}$ 
The empirical relation of Gunn (1978), as given by equation (T1-15), was used for the interphase heat transfer coefficient. Here, $R e_{\mathrm{p}}$ and $\mathrm{Pr}$, respectively, represent the particle Reynolds number and Prandtl number. It is noteworthy that the Reynolds number is based on the superficial relative velocity, $\alpha_{g}\left|\vec{v}_{s}-\vec{v}_{g}\right| \cdot$ Sometimes, the incorrect expression of Reynolds number based on relative velocity has been used in the literature.

\section{Numerical simulation conditions}

The conditions of the experimental results of Zhao et al. (2008a) and Liu et al. (2008) were used, respectively, for simulation of 2DSB with and without draft plates containing glass beads. A schematic of both systems is shown in Fig. 1.

The corresponding physical and numerical parameters selected for the present simulations are listed in Table 2.

The particle-particle restitution coefficient, $e_{\mathrm{s}}$, is defined as a measurement of the energy dissipation during the collisions between the particles. A perfectly elastic collision has a coefficient of restitution of 1 , while the corresponding coefficient for a perfectly plastic collision is zero.

According to the results obtained by Hosseini et al. (2013), by increasing the particle-particle coefficient of restitution, the fountain height and velocity of particles decreases.

In the present research, the particles are the same; thus, for 2DSB with and without draft plates $e_{\mathrm{s}}=0.91$ was chosen. Note that the CFD model with $e_{\mathrm{s}}=0.91$ showed a close agreement with the experimental dataamong the

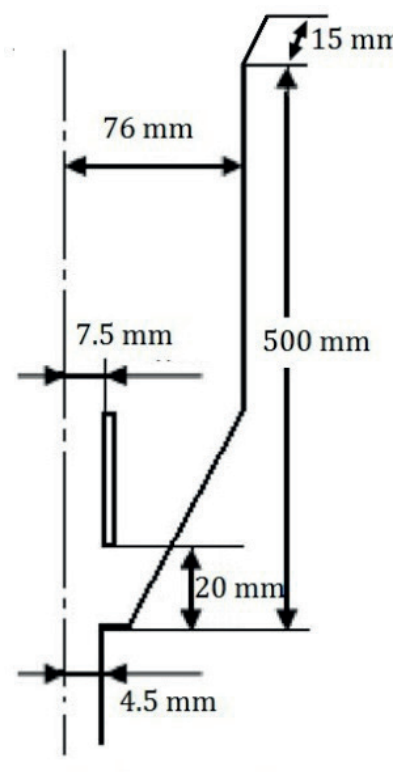

(a) with draft plates

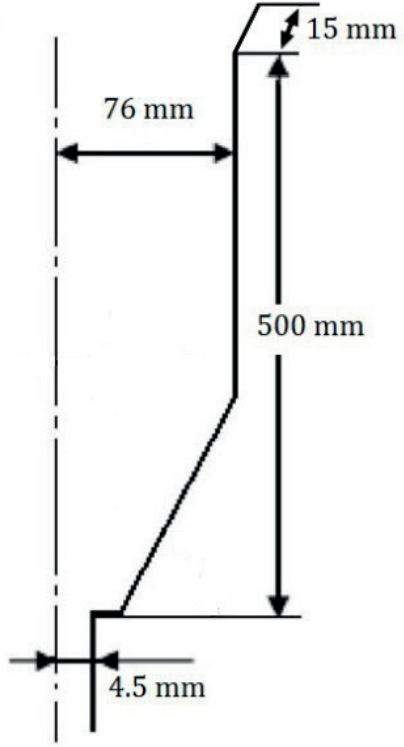

(b) without draft plates
Figure 1. Schematic of the 2DSB column setups with dimensions in $\mathrm{mm}$.

other values of this parameter.

The wall-particle restitution coefficient, $e_{\mathrm{w}}$, is a measure of the elasticity of the collision between wall and particles. According to the previous works (Hosseini, 2015; Hosseini et al., 2014), $e_{\mathrm{w}}=0.2$ was chosen for both systems.

The specularity coefficient, $\varphi$, is a modelling parameter that is used to determine whether the wall is smooth $(\varphi \rightarrow 0)$ or rough $(\varphi \rightarrow 1)$ and define the solids tangential velocity imposed at the wall. The

Table 2. Physical and numerical parameters selected for the present simulations

\begin{tabular}{|c|c|c|c|}
\hline Description & Symbol (unit) & 2DSB without internal & 2DSB with draft plates \\
\hline Particle diameter & $\mathrm{d}_{\mathrm{s}}(\mathrm{mm})$ & 2 & 2 \\
\hline Particle density & $\rho_{s}\left(\mathrm{~kg} / \mathrm{m}^{3}\right)$ & 2380 & 2380 \\
\hline Gas density & $\rho_{g}\left(\mathrm{~kg} / \mathrm{m}^{3}\right)$ & 1.22 & 1.22 \\
\hline Static bed depth & $\mathrm{H}_{0}(\mathrm{~mm})$ & 100 & 100 \\
\hline Maximum solid volume fraction & $\alpha_{s, \max }{ }^{(-)}$ & 0.6 & 06. \\
\hline Particle-particle restitution coefficient & $e_{\mathrm{s}}(-)$ & 0.91 & 0.91 \\
\hline Particle-wall restitution coefficient & $e_{\mathrm{w}}(-)$ & 0.2 & 0.2 \\
\hline Specularity coefficient & $\varphi(-)$ & 0.05 & 0.1 \\
\hline Gas superficial velocity & $U_{\mathrm{s}}(\mathrm{m} / \mathrm{s})$ & 1.95 & 1.35 \\
\hline Sphericity & $\Phi_{(-)}$ & 1 & 1 \\
\hline Specific heat capacity of solids & $\mathrm{C}_{\mathrm{pg}}(\mathrm{kJ} / \mathrm{kg} . \mathrm{K})$ & 0.84 & 0.84 \\
\hline Specific heat capacity of gas & $\mathrm{C}_{\mathrm{ps}}(\mathrm{kJ} / \mathrm{kg} \cdot \mathrm{K})$ & 1.006 & 1.006 \\
\hline
\end{tabular}


parameter will vary depending on a number of factors, including the material of the wall, the type of particles used and the sloping/geometry of the walls. By increasing the specularity coefficient the fountain height reduces because of the enhancement in friction between particles and the wall, resulting in reduction of fountain height and particle velocity. Hosseini et al. (2014) showed that the sensitivity of specularity coefficient in the draft tube region of a cylindrical spouted bed is much higher than in the other regions. Lan et al. (2012) showed that a small specularity coefficient of $\varphi=0.05$ give good predictions for a conventional cylindrical spouted bed including Geldart D particles. In this study, $\varphi=0.05$ and 0.1 give the best predictions for 2DSB with and without draft plates, respectively.For thesake of brevity, steps in determining these modeling parametershave not been shown here.

It should be noted that experimental values associated with each of the abovementioned coefficients are not available and they are estimated previously as fitting parameters. More information about choosing $e_{\mathrm{s}}, e_{\mathrm{w}}$ and $\varphi$ for CFD simulation of gas-solid systems is available in studies of Hosseini et al. (2013, 2014), Lan et al. (2012), Du et al. (2006), Huilin et al. (2004), Hosseini (2015) and Setarehshenas et al. (2016).

\section{Solution procedure}

A commercial grid-generation tool, GAMBIT 2.2, is used to create the geometry and computational grid. In addition, the CFD package (ANSYSFLUENT 15) is used to simulate the hydrodynamics and heat transfer of both systems. The set of governing equations described above is solved by a finite control volume technique. The phase coupled SIMPLE algorithm, which is an extension of the SIMPLE algorithm for multiphase flow, has been used for the pressure-velocity coupling and correction. The momentum and volume fraction equations have been discretized by a first-order upwind scheme. A transient simulation has been adopted; the time step in the range of 0.00001-0.002 with 50 iterations per time step is used. A convergence criterion of $10^{-3}$ for each scaled residual component has been specified for the relative error between two successive iterations. Due to the behaviour of the particles and to save the computational time, symmetry frameworks of 3D were used. Fig. 2 shows the numerical grid for both systems. As shown in Fig. 2, grids at the center of the bed are smaller than near the lateral wall and grids at the bottom of the bed are smaller than at the top of the bed. Total number of cells for 2DSB without draft plates is 96000 and for 2DSB with draft plates is 94810 cells.It should be pointed out that the grid independent study has been carried out in the previous work (Hosseini et al., 2015).

\section{Initial and boundary conditions}

A Dirichlet boundary condition at the bottom of the bed is used to specify a uniform gas inlet velocity. The outflow condition with zero velocity gradient is specified at the top of the freeboard. A no-slip boundary condition for all walls is assumed for the gas phase. The particle normal velocity is set to zero at the wall. The Johnson and Jackson

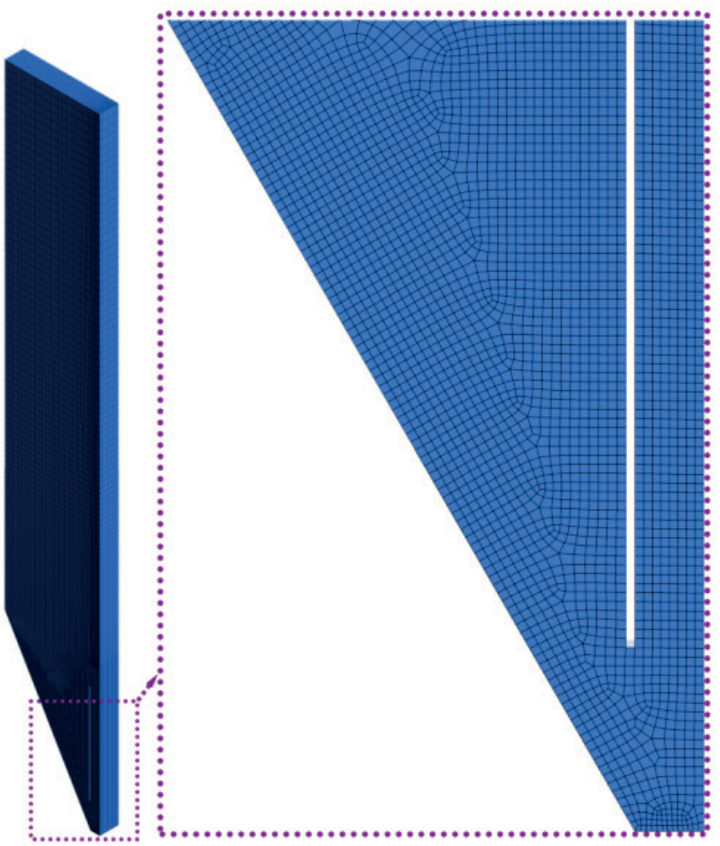

(a)
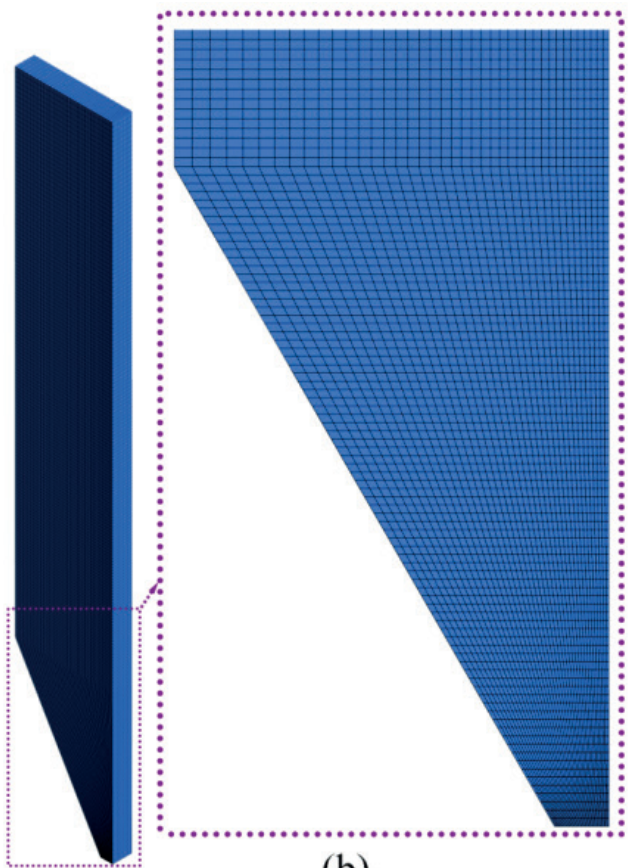

(b)

Figure 2. Grid structures for the computational domains. (a) 2DSB with draft plates. (b) 2DSB without draft plates. 
(1987) wall boundary condition is used for the tangential velocity and granular temperature of the solid phase at the wall. These include the front and back walls as well. The inlet air temperature is transient as shown in Fig. 3 and that is implemented by means of UDF. The walls are assumed to be adiabatic. Initially, the particle concentration in the spouted bed is specified, and gas velocity inside the spouted bed is set to zero. The particle concentration in the freeboard region is also set to zero.

\section{RESULTS AND DISCUSSION}

\section{Time averaged velocity of particles along the bed axis}

As mentioned before, Hosseini et al. (2015) showed that the $2 \mathrm{D}$ simulation of a thin rectangular spouted bed without draft plates is not adequate for predicting the corresponding experimental data. They, however, obtained reasonable results for the time-averaged axial velocity distribution of particles by considering the thin thickness of the bed intheir CFD model.In the present study, the influence of bed thickness of a pseudo 2D spouted bed with draft plates is evaluatedand the corresponding results are presented in Fig. 4.

To provide an appropriate comparison between the 2D and 3D models the simulations were performed for the optimal values of modeling parameters such as particleparticle restitution coefficient, particle-wall restitution coefficient, and specularity coefficient for each case. For the 2D model, several values of specularity were used. It is seen that the numerical results of the 2D modeling are quite sensitive to the value of the specularity coefficient. The increase of the specularity parameter leads to the decrease of the fountain height due to the increase of friction between the particles and the wall. Moreover, the particle velocity along the bed axis decreases with the increase of the specularity coefficient. Fig. 4 also clearly shows that the $3 \mathrm{D}$ CFD results better represent the experimental data in comparison with the $2 \mathrm{D}$ modeling results.

Fig. 5 shows the time-averaged velocity distribution of particles in the y direction for both spouted beds with and without draft plates. In order to validate the CFD results, the experimental data of Zhao et al. (2008a) and Liu et al.(2008) are reproduced in this figure. It is clearly seen that the CFD results are in close agreement with the experimental observations for both systems.

As shown in Fig. 5, the particle velocity in both systems at $y=17.2 \mathrm{~cm}$ (top of the fountain) reaches zero and particles come back to the annulus region. Fig. 5 also shows that thebehavior of particle circulation in spouted beds with and without draft plates is somewhat different. Shuyan et al. (2010) also obtained the same trend of timeaveraged velocity of particles along the bed axis for the pseudo 2D spouted bed operated by Zhao et al. (2008a) using the FLUENT code.

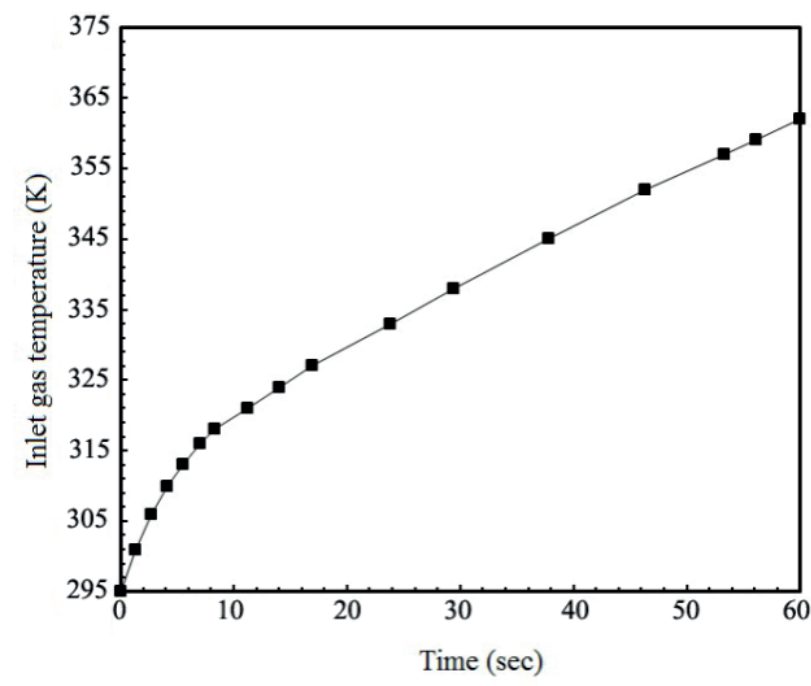

Figure 3. Transient inlet air temperature ramp for the 2DSB with and without draft plates.

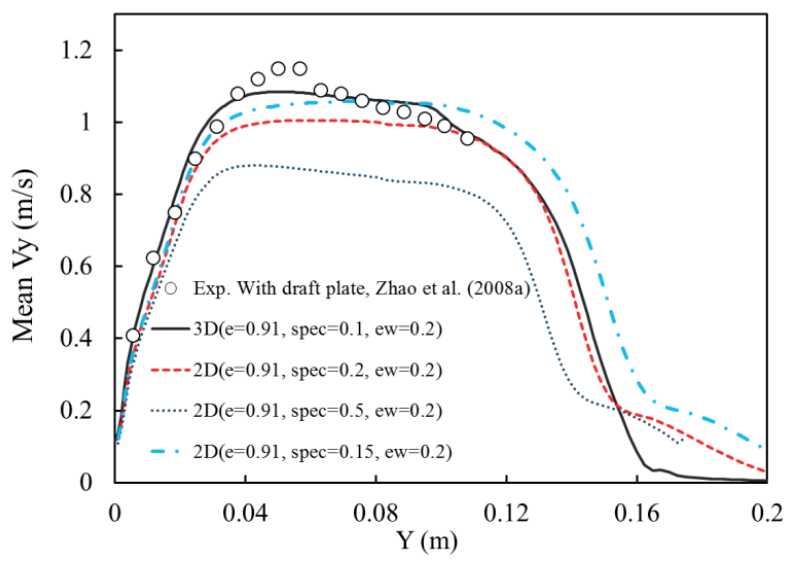

Figure 4. Computed and measured vertical particle velocities along the bed axis for 2DSB with draft plates for 2D and 3D models.

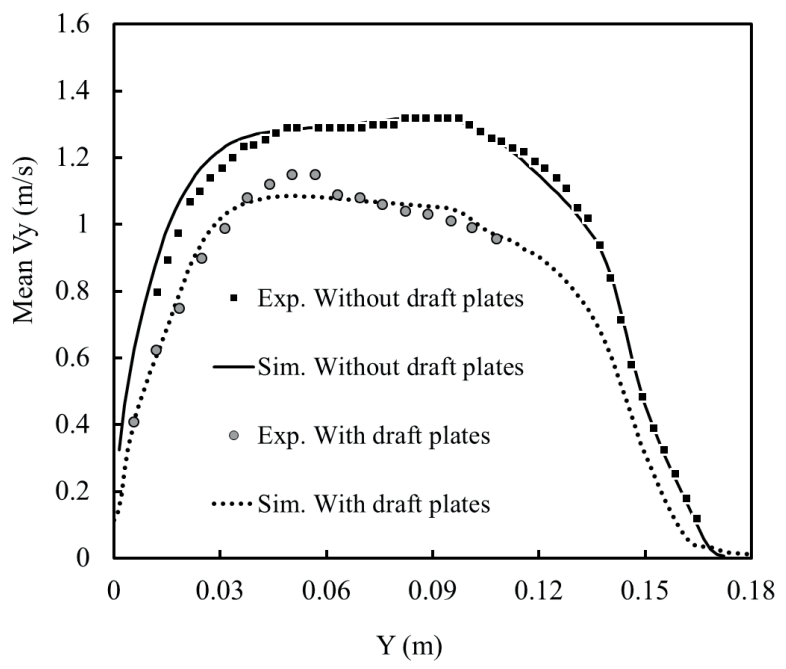

Figure 5. Computed and measured vertical particle velocities along the bed axis for 2DSB with and without draft plates. 
Fig. 6 shows the time-averaged particle velocity in the spout region for two levels of the bed. In order to validate the CFD results, the computational results are compared with the corresponding experimental data in this figure. A good agreement between the CFD results and measurements is observed for both systems, especially for 2DSB without draft plates (Fig. 6b). This figure shows that the particle velocities reach their peaks at the bed axis for both systems and at various levels, and then decrease toward the spoutannulus interface and draft plates, respectively, for 2DSB without and with draft plates.

For 2DSB without draft plates, Fig. 6b shows that the spout radius (identified as the point where the particle velocity passes through zero) enlarges from about $1.4 \mathrm{~cm}$ to $1.8 \mathrm{~cm}$ as the bed level increases from $7.6 \mathrm{~cm}$ to $9.12 \mathrm{~cm}$. The results presented in Fig. 6a, however, are for particle velocities between the draft plates. It is seen that, for the case of 2DSB with draft plates, the particle velocities are positive as the particles are transported upward in this region. Earlier, Sutkar et al. (2013a, 2013b) reported a numerical and experimental study of a pseudo-2D spout fluidized bed containing glass beads and $\gamma$-aluminum oxide particles. The spout fluidized beds combine advantages of both spouted beds and fluidized beds. Sutkar et al. (2013a, 2013b) found that the particle velocity profiles through the draft plates are roughly flat, showing stronger resemblance with the results presented in Fig 6a. Their findings suggested the formation of particle clusters at various heights within the draft plates.

Fig. 7 compares the predicted particle velocity vectors for 2DSB with draft plates with the experimental data of Zhao et al. (2008a). According to CFD and experimental results, the velocity vectors inside the plates (spout region) are upwards and outside the plates (annulus region) are downwards. Similarly, Fig. 8 compares the simulated particle velocity vectors for 2DSB without draft plates with the experimental data of Liu et al. (2008a). Both Figs 7 and 8 show a fair agreement between the CFD results and the experimental data.

From Figs. 7 and Fig. 8 it is clearly seen that, when the draft plates is used in 2DSB, the particle velocity in the annulus region is entirely downward,while for 2DSB without draft plates the particlevelocity is upward near the central spout region and decreases toward the edge of the spout region, and the particle velocity changesitsdirection to downward in the annulus region.

\section{Particle volume fraction}

Comparison of the time averaged particle volume fraction for 2DSB with and without draft plates is shown in Fig. 9. This Figure shows that the particle concentrations in 2DSB without draft plates at the spout and fountain regions are relatively higher than $2 \mathrm{DSB}$ with draft plates as the particle concentrations for 2DSB with draft plates
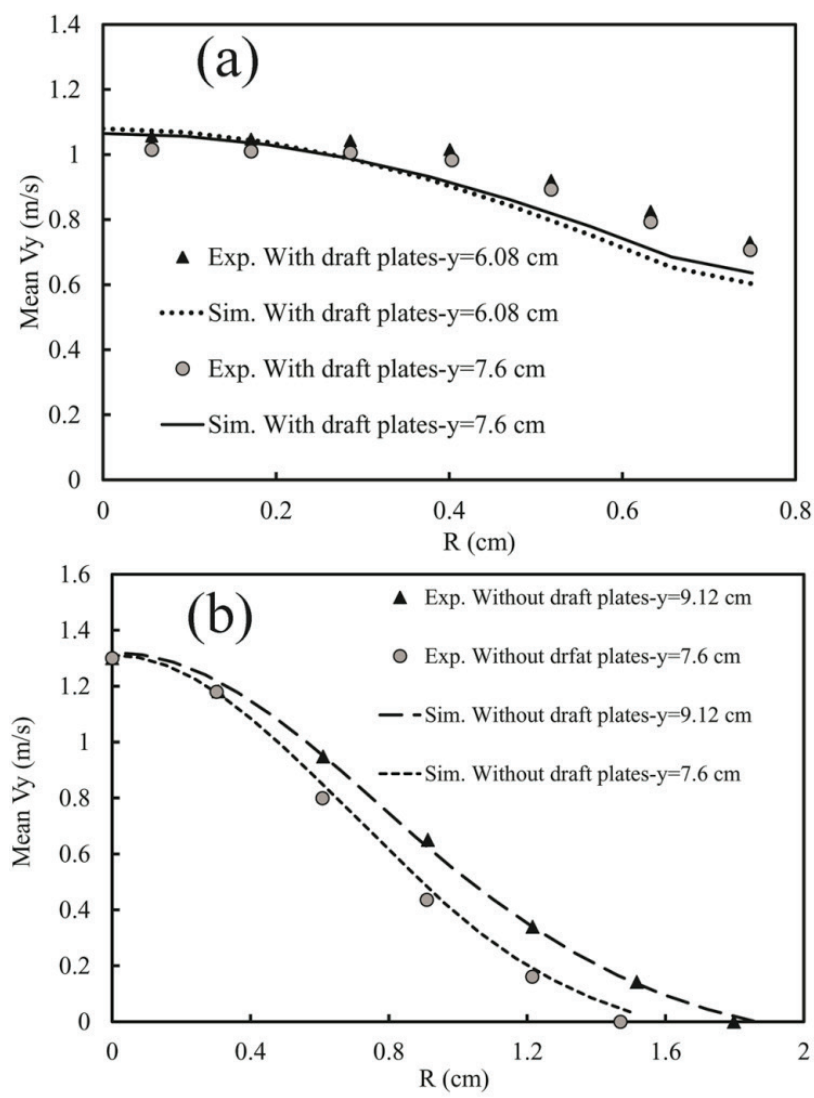

Figure 6. Computed and measured vertical particle velocity profiles in the spout regionat different bed levels for 2DSB with and without draft plates.

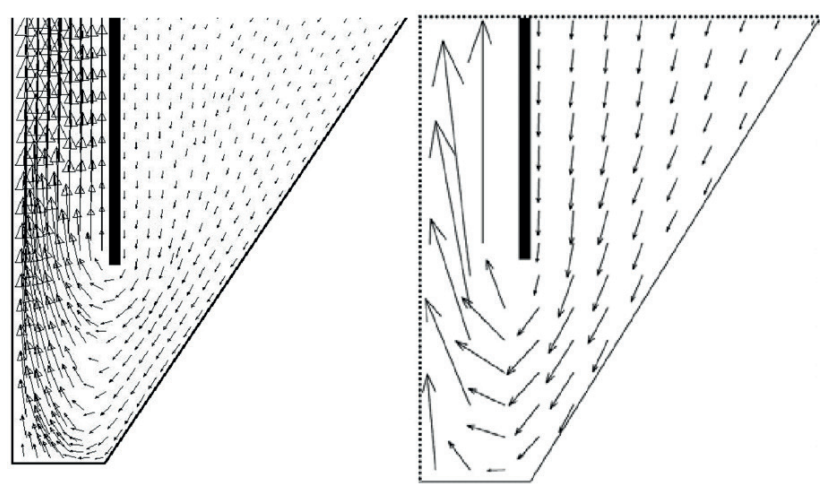

(a) Simulation

(b) Experiment

Figure 7. Comparison of computational time-averaged particles velocity vectors in the $2 \mathrm{DSB}$ with draft plates with the experimental data of Zhao et al. (2008a).

at the spout and fountain regions are considerably dilute. This behavior of the particles agrees well withthe earlier findings of Hosseini et al. (2014) and Hosseini (2015) in their simulation of a gas-solid cylindrical spouted bed with draft tube.

It is interesting to note that the present simulation results are in a close agreement with the experimental data, whereas only qualitative agreements were reported in the 
earlier DEM and 2D TFM approaches (Moradi et al., 2013; Zhao et al., 2008b; Hosseini et al., 2010). Therefore, it may be concluded that the $2 \mathrm{D}$ simulation is not adequate for predicting the experimental data of thin spouted bed (2DSB) with and without draft plates, as the effect front and back walls become quite important.

\section{Temperature distribution}

In the previous section, by evaluating some important hydrodynamic parameters such as particle velocity along the bed axis, radial distribution of axial particle velocity at different levels, particle velocity vectors and particle volume fraction, the accuracy of the CFD model was improved. In this part, with the verified hydrodynamics model and solving energy and relevant constitutive equations, the thermal behaviour of spouted beds with and without draft plates is studied.

Due to the lack of sufficient experimental data regarding heat transfer, especially temperature distribution of the particles in the conical spouted beds, the qualitative behavior of the particle temperature distribution in 2DSB with and without draft plates is evaluated by solving the verified hydrodynamics model and energy model that has been validated previously by other researchers (Patil et al., 2006; Armstrong et al., 2010), simultaneously. In this research, the gas inlet temperature increases with time as shown in Fig. 3.

Fig. 10 shows the particle temperature distribution in 2DSB with and without draft plate for times of 10 and 30 s. As mentioned before, the gas inlet temperature increases with time, that results in the time dependenceof particle temperaturein the beds, with and without draft plates. This issue is clearly shown in the figure since, by increasing the simulation time, the particle temperature increasesin the entire beds. It is found that the highest particle temperature appears in the fountain region compared to the other regions, for both systems. These behaviors of the particle temperature distribution were also observed by other researchers forthin rectangular spouted beds (Brown and Lattimer, 2013; Fattahi et al., 2015; Hosseini et al., 2015). Moreover, Swasdisevi et al. (2005) used DEM and simulated a 2DSB with draft plates for the case that the static bed height was considerable higher thanthe conical section. They also found that the particle temperature in the fountain and spout regions is higher than that in the annulus zone.

From Fig. 10, it is also observed that, in the 2DSB without draft plates, there is a region in the annulus zone in which the particles circulate with low velocity and have the lowest temperature. For 2DSB with draft plates, however, the lowest particle temperature occurs adjacent to the draft plates. At the present time the experimental data to confirm these trends are not available. Of course, obtaining detailed experimental data for these systems is highly desirable for further validation of the model.

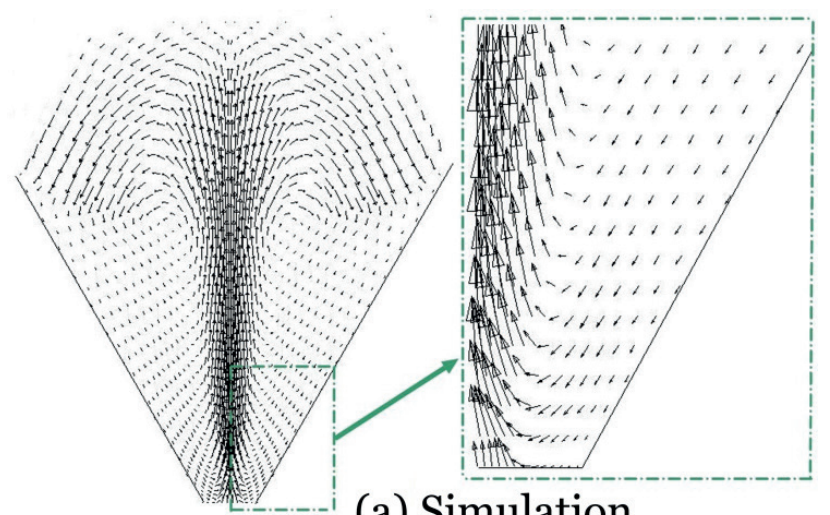

(a) Simulation

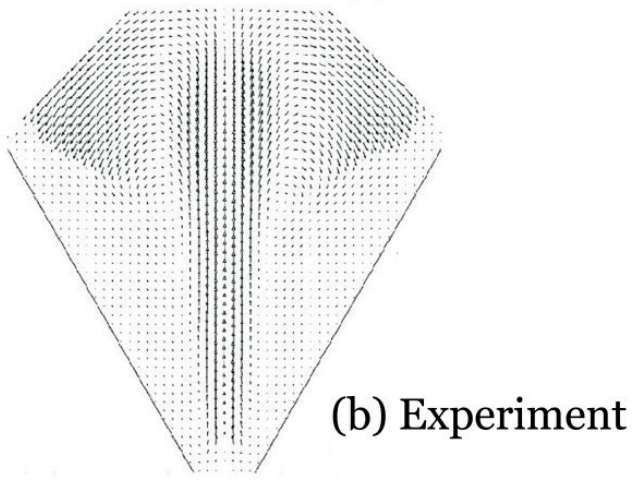

Figure 8. Comparison of computational time-averaged particles velocity vectors in the 2DSB without draft plates with the experimental data of Liu et al. (2008).

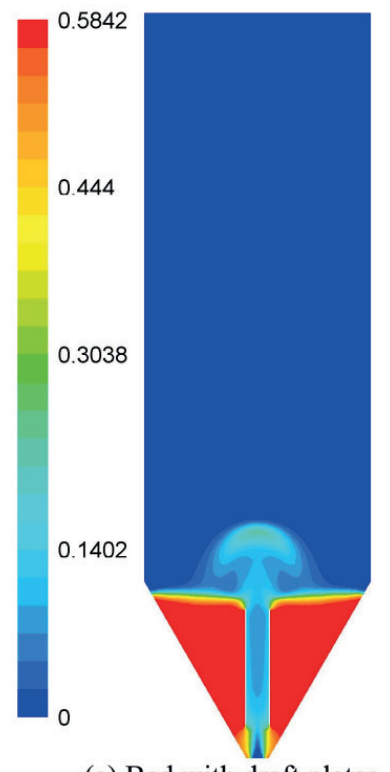

(a) Bed with draft plates

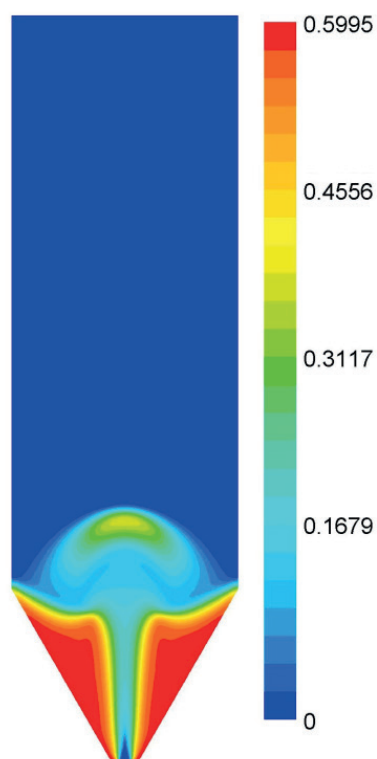

(b) Bed without draft plates
Figure 9. Time-averaged particle volume fraction for 2DSB with and without draft plates.

Fig. 11 shows the time-averaged gas temperature for gas velocities shown in that figure for these beds. It is observed that the maximum gas temperature occurs at the nozzle input, in the spout region, for both systems, 

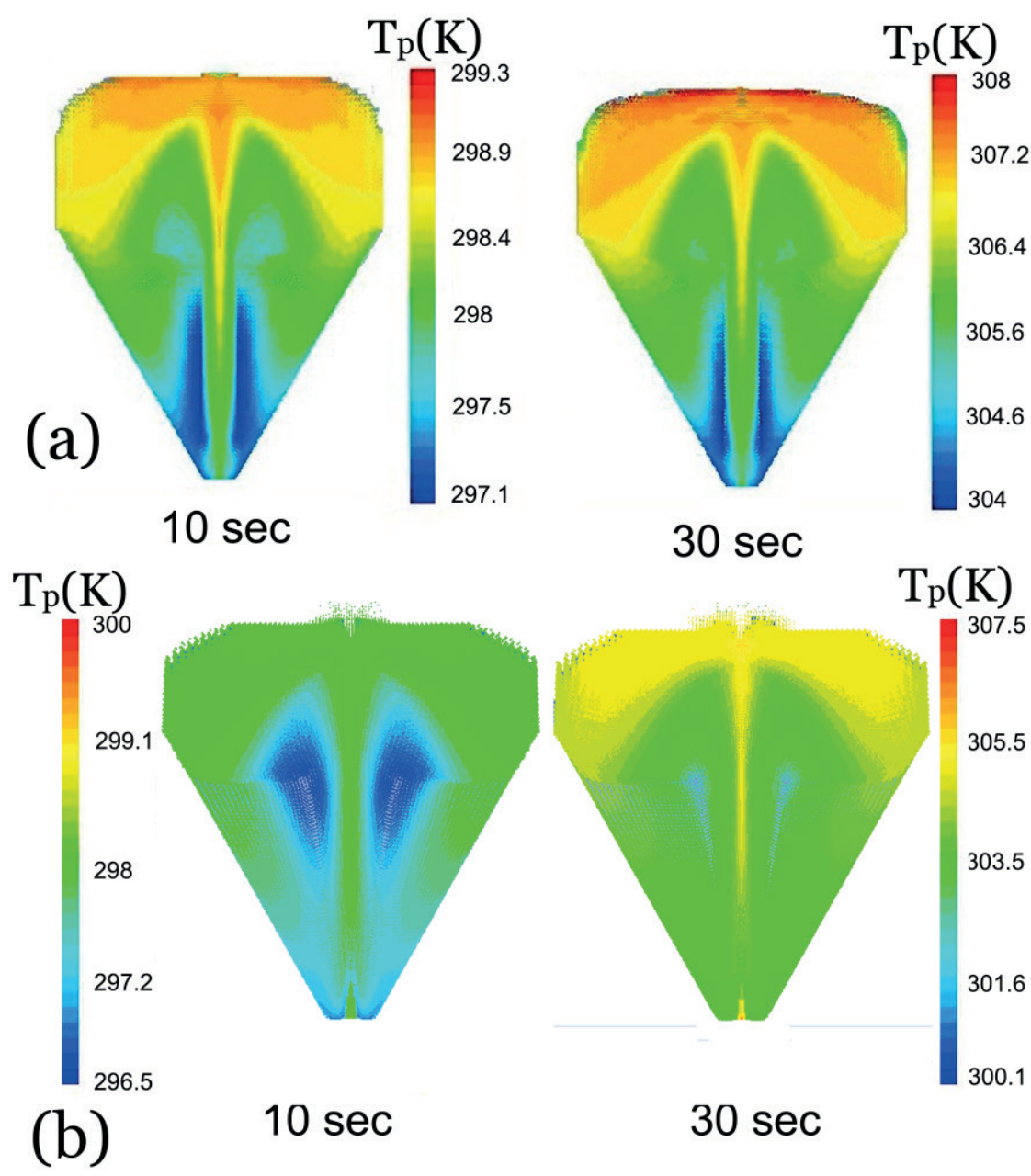

Figure 10. Particle temperature distribution in: (a) 2DSB with draft plates; (b) 2DSB without draft plate for various times of 10 and $30 \mathrm{~s}$.

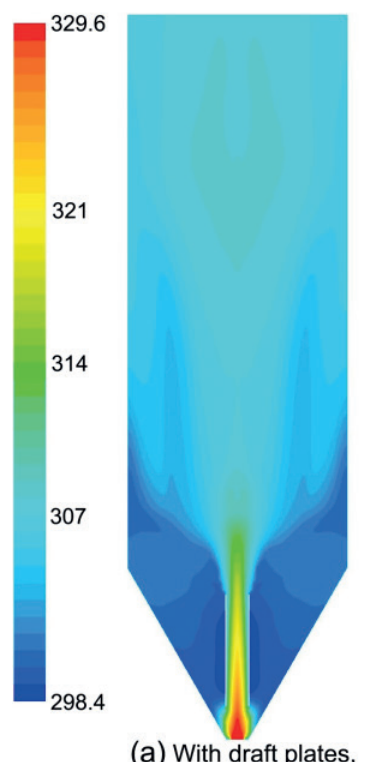

(a) With draft plates,
$U=1.35 \mathrm{~m} / \mathrm{s}$

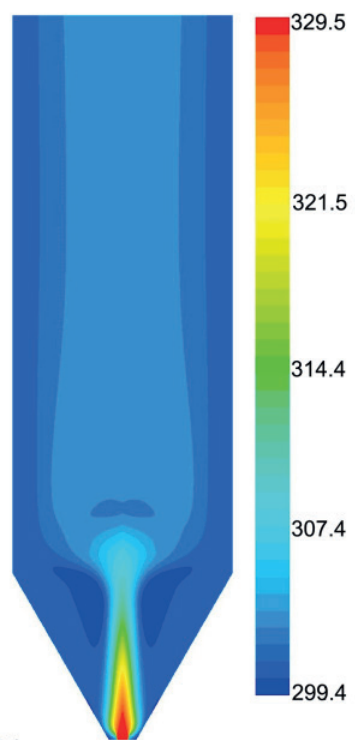

(b) Without draft plates,

$\mathrm{U}=1.95 \mathrm{~m} / \mathrm{s}$

Figure 11. Time-averaged gas temperature distributions in 2DSB with and without draft plates. 
while in the 2DSB with draft plates the highest gas temperature covers a wider range of spout zone in comparison with the conventional one. This is due to the lower particle concentration in the draft tube, resulting in lower heat exchange between the phases in that region. It is worth mentioning that Makibar et al. (2011) studied the hydrodynamic and heat transfer performance of a cylindrical-conical spouted bed reactor including a draft tube that was designed for pyrolysis of biomass wastes. Their results revealed that the maximum gas temperature appears at the inlet of the gas phase in the spout zone. In the fountain region, temperature drops are considerable due to the lower gas velocity. These observations further confirm the present results. In summary, Figs. 10 and 11 show that the heat transfer behaviour for the systems with and without draft plates are quite different, particularly in thedetails of flow and temperature distribution.

\section{CONCLUSIONS}

The hydrodynamics and the transient gas to particle heat transfer in a 2DSB with and without draft plates were studied using the Eulerian-Eulerian two-fluid model (TFM) in conjunction with the kinetic theory of granular materials. The Gidaspow drag model was used to obtain the interphase interaction of gas and solid phases. The boundary condition of Johnson-Jackson was applied to characterize the particle-wall collisions including sliding. The empirical relation of Gunn (1978) for the interphase heat transfer coefficient that is already available in FLUENT 15 was used in these simulations. In addition, the frictional viscosity of Johnson and Jackson (1987) was included in the model. In the present simulations, the inlet gas temperature increased with time. The influence of the presence of draft plates on the hydrodynamics and heat transfer behavior of solid particles in the spouted beds was evaluated. The main conclusions are:

1) The proposed modelis capable of predictingthe hydrodynamics behaviorof2DSB with and without draft plates. In particular, themean vertical velocity of particles along the bed axis, the lateral profiles of vertical particle velocity at different bed heights, and particle velocity vector fields in the beds are predicted reasonably well. The presented model improves the previous simulations reported in the literature due to the inclusion of the effects of front and back walls in the model.

2) The CFD results show that the particle volume fraction in the spout and fountain regions of the spouted bed with draft plates is considerably lower than that in a conventional spouted bed without draft plates.

3) Concerningheat transfer from the gas phase to the solid phase, significant differences between the temperature distributions of gas and solid phases in spouted beds with and without draft plates were observed.

4) The highest particle temperature appears in the fountain region for both systems. In the 2DSB without draft plates, there is a region in the annulus zone in which the particles circulate with low velocity, and this region has the lowest temperature. In the 2DSB with draft plates, however, the lowest particle temperature occurs adjacent to the draft plates.

5) Comparing of the gas temperature distributions in the 2DSB with and without draft plates, the maximum gas temperature occurs at the nozzle outlet in the spout region for both systems. In the fountain region, there is a large temperature drop due to the lower gas velocity for both systems.

\section{NOMENCLATURE}

\begin{tabular}{|c|c|}
\hline $\mathrm{C}_{\mathrm{D}}$ & : drag coefficient $[-]$ \\
\hline $\mathrm{d}_{\mathrm{s}}$ & : particle diameter $[\mathrm{m}]$ \\
\hline$D_{p}^{s}$ & : depth of the bed $[\mathrm{m}]$ \\
\hline $\mathrm{H}^{\mathrm{p}}$ & : vessel height $[\mathrm{m}]$ \\
\hline W & : width of the bed $[\mathrm{m}]$ \\
\hline $\mathrm{e}_{\mathrm{s}}$ & : particle-particle restitution coefficient [-] \\
\hline$\sigma^{\circ}$ & : acceleration due to gravity $\left[\mathrm{m} / \mathrm{s}^{2}\right]$ \\
\hline $\begin{array}{l}\mathrm{g}_{0} \\
\mathrm{H}_{0}\end{array}$ & $\begin{array}{l}\text { : radial distribution coefficient }[-] \\
: \text { static bed depth }[\mathrm{mm}]\end{array}$ \\
\hline $\mathrm{I}$ & : stress tensor $[-]$ \\
\hline $\mathrm{I}_{2 \mathrm{D}}$ & $\begin{array}{l}\text { second invariant of the deviatoric stress } \\
\text { tensor }[-]\end{array}$ \\
\hline $\mathrm{k}_{\grave{\mathrm{E}}_{\mathrm{s}}}$ & : diffusion coefficient for granular energy $[\mathrm{kg} / \mathrm{m} \mathrm{s}]$ \\
\hline$\hat{a}$ & $\begin{array}{l}\text { : gas/solid momentum exchange coefficient } \\
{\left[\mathrm{kg} / \mathrm{m}^{3} \mathrm{~s}\right]}\end{array}$ \\
\hline$\hat{a}_{\text {Ergun }}$ & $\begin{array}{l}\text { : gas/solid momentum exchange coefficient } \\
\text { by Ergun equation }\left[\mathrm{kg} / \mathrm{m}^{3} \mathrm{~s}\right]\end{array}$ \\
\hline$\hat{a}_{W e n-Y u}$ & $\begin{array}{l}\text { : gas/solid momentum exchange coefficient } \\
\text { calculated by Wen-Yu equation }\left[\mathrm{kg} / \mathrm{m}^{3} \mathrm{~s}\right]\end{array}$ \\
\hline $\mathrm{P}$ & : pressure $\left[\mathrm{N} / \mathrm{m}^{2}\right]$ \\
\hline $\mathrm{P}_{\mathrm{s}}$ & : solids pressure $\left[\mathrm{N} / \mathrm{m}^{2}\right]$ \\
\hline$t^{s}$ & : Time $[\mathrm{s}]$ \\
\hline $\mathrm{U}$ & : superficial gas velocity $[\mathrm{m} / \mathrm{s}]$ \\
\hline$v_{i}$ & : velocity $[\mathrm{m} / \mathrm{s}]$ \\
\hline $\mathrm{U}_{\mathrm{mf}}^{l}$ & : minimum fluidization velocity $[\mathrm{m} / \mathrm{s}]$ \\
\hline $\mathrm{T}$ & : temperature $[\mathrm{K}]$ \\
\hline $\mathrm{K}$ & : thermal conductivity $[\mathrm{w} / \mathrm{m} . \mathrm{K}]$ \\
\hline $\mathrm{C}_{\mathrm{p}}$ & : specific heat capacity $[\mathrm{J} / \mathrm{kg} . \mathrm{K}]$ \\
\hline $\mathrm{h}$ & : enthalpy $[\mathrm{J} / \mathrm{kg}]$ \\
\hline $\mathrm{Nu}$ & : Nusselt number [-] \\
\hline $\mathrm{Re}$ & : Reynolds number [-] \\
\hline $\operatorname{Pr}$ & : Prandtl number [-] \\
\hline
\end{tabular}




\section{Greek letters}

$\alpha_{i} \quad$ : volume fraction [-]

$\tilde{\mathrm{a}}_{\mathrm{s}} \quad$ : the collisional dissipation of energy $\left[\mathrm{kg} / \mathrm{s}^{3} \mathrm{~m}\right]$

$\Theta_{s}:$ granular temperature $\left[\mathrm{m}^{2} / \mathrm{s}^{2}\right]$

$\lambda_{s} \quad$ : solid bulk viscousity $[\mathrm{kg} / \mathrm{m} \mathrm{s}]$

$\mu_{i} \quad$ : shear viscosity $[\mathrm{kg} / \mathrm{m} \mathrm{s}]$

$\rho_{i} \quad:$ density $\left[\mathrm{kg} / \mathrm{m}^{3}\right]$

$\hat{\mathrm{O}}_{i} \quad:$ stress tensor $\left[\mathrm{N} / \mathrm{m}^{2}\right]$

$\phi \quad$ : angle of internal friction [deg]

$\varphi \quad$ : specularity coefficient [-]

\section{Subscripts}

col collision

fr $\quad$ : friction

kin : kinetic

g : : gas

$\mathrm{p} \quad$ : particle

q $\quad$ : phase type (solid or gas)

s : solids

$\mathrm{T} \quad$ : stress tensor

\section{REFERENCES}

Aguado, R., Olazar, M., San Jose, M. J., Gais'an, B., and Bilbao, J., Wax formation in the pyrolysis of polyolefins in a conical spouted bed reactor. Energy and Fuels, 16, 1429 (2002).

Arabiourrutia, M., Lopez, G., Elordi, G., Olazar, M., Aguado, R., and Bilbao, J., Product distribution obtained in the pyrolysis of tyres in a conical spouted bed reactor. Chemical Engineering Science, 62, 5271 (2007).

Armstrong, L.M., Gu, S., and Luo, K.H., Study of wall-to-bed heat transfer in a bubbling fluidised bed using the kinetic theory of granular flow. International Journal of Heat and Mass Transfer, 53, 4949 (2010).

Azizi, S., Hosseini, S.H., Moraveji, M., and Ahmadi, G., CFD modeling of a spouted bed with a porous draft tube. Particuology, 8, 415 (2010).

Brown, S.L., and Lattimer, B.Y., Transient gas-to-particle heat transfer measurements in a spouted bed. Experimental Thermal and Fluid Science, 44, 883 (2013).

Deen, N.G., Annaland, M.V., Van der Hoef, M.A., and Kuipers, J.A.M., Review of Discrete Particle Modeling of Fluidized Beds. Chemical Engineering Science, 62, 28 (2007).

Du, W., Bao, X., Xu, J., and Wei, W., Computational fluid dynamics (CFD) modeling of spouted bed: Influence of frictional stress, maximum packing limit and coefficient of restitution of particles. Chemical Engineering Science, 61, 4558 (2006).

Duarte,C.R., Murata,V.V. and Barrozo,M.A.S., A study of the fluid dynamics of the spouted bed using CFD. Brazilian Journal of Chemical Engineering, 22, 263 (2005).
Elordi, G., Olazar, M., Lopez, G., Amutio, M., Artetxe, M., Aguado, R., and Bilbao, J., Catalytic pyrolysis of HDPE in continuous mode over zeolite catalysts in a conical spouted bed reactor. Journal of Analytical and Applied Pyrolysis, 85, 345 (2009).

Epstein, N., and Grace, J. R., Spouted and spout-fluid beds fundamentals and applications, Cambridge University Press, 2011.

Fattahi, M., Hosseini, S.H., and Ahmadi, G., CFD simulation of transient gas to particle heat transfer for fluidized and spouted regimes. Applied Thermal Engineering, 105, 385, (2015).

Filho, M.P., Rocha, S.C.S., and Lisboa, A.C.L., Modeling and experimental analysis of polydispersed particles coating in spouted bed. Chemical Engineering and Processing, 45, 965 (2006).

Gidaspow, D., Bezburuah, R., and Ding, J., Hydrodynamics of circulating fluidized beds. Kinetic theory approach, fluidization VII, Proceedings of the Seventh Engineering Foundation Conference on Fluidization, p. 75-82 (1992).

Gunn, D.J., Transfer of Heat or Mass to Particles in Fixed and Fluidised Beds. International Journal of Heat Mass Transfer, 21, 467-476 (1978).

Hamzehei, M., Rahimzadeh, H., and Ahmadi, G., Computational and Experimental Study of Heat Transfer and Hydrodynamics in a 2D Gas-Solid Fluidized Bed Reactor, Industrial Engineering and Chemical Research, 49, 5110-5121 (2010).

Hosseini, S.H., Ahmadi, G., and Olazar, M., CFD simulation of cylindrical spouted bed by the kinetic theory of granular flow. Powder Technology, 246, 303 (2013).

Hosseini, S.H., Ahmadi, G., and Olazar, M., CFD Study of Particle Velocity Profiles inside a Draft Tube in a Cylindrical Spouted Bed with Conical Base. Journal of Taiwan Institute Chemical Engineers, 45, 2140 (2014).

Hosseini, S.H., Ahmadi, G., SaeediRazavi, B., and Zhong, W., Computational Fluid Dynamic Simulation of Hydrodynamic Behavior in a Two-Dimensional Conical Spouted Bed.Energy Fuels, 24, 6086 (2010).

Hosseini, S.H., Fattahi, M., and Ahmadi, G., CFD Study of hydrodynamic and heat transfer in a 2D spouted bed: Assessment of radial distribution function. Journal of Taiwan Institute Chemical Engineers,58, 107 (2016).

Hosseini, S.H., Fattahi, M., and Ahmadi, G., Hydrodynamics Studies of a Pseudo 2D Rectangular Spouted Bed by CFD. Powder Technology, 279, 301 (2015).

Hosseini, S.H., Influences of Geometric Factors on CFD Results of a Draft Tube Cylindrical Spouted Bed.Progress in Computational Fluid Dynamics, 16, 78 (2016).

Hosseini, S.H., Zivdar, M., and Rahimi, R., CFD simulation of gas-solid flow in a spouted bed with a nonporous draft tube. Chemical Engineering and Processing, 48, 1539 (2009).

Huilin, L., Gidaspow, D., Bouillard, J., and Wentie, L., Hydrodynamic Simulation of Gas-Solid Flow in a Riser Using Kinetic Theory of Granular Flow. Chemical Engineering Journal, 95, 1 (2003).

Huilin, L., He, Y., Liu, W., Ding, J., Gidaspow, D., and Bouillard, J., Computer simulation of gas-solid flow in spouted beds using kinetic frictional stress model of granular flow. Chemical Engineering Science, 59, 865 (2004). 
Johnson, P.C., and Jackson, R., Frictional-collisional constitutive relations for granular materials with application to plane shearing. Journal of Fluid Mechanics, 176, 67 (1987).

Kalwar, M.I., Raghavan, G.S., and Mujumdar, A.S., Circulation of particles in two dimensional spouted beds with draft plates. Powder Technology, 77, 233 (1993).

Kmiec, A., and Jabarin, N. A., Hydrodynamics, heat and mass transfer during coating of rings in a spouted bed. In Proceedings of the 12th International Drying Symposium (IDS), ed. Kerkhof P. J. A.M., Coumans W. J., and Mooiweer G. D., (Noordwijkerhout, Netherlands: Elsevier), CD-ROM, Paper No. 19, 1 (2000).

Kmiec, A., Kucharski, J. and Mielczarski. S., Hydrodynamics and kinetics during drying of coal in a spouted bed dryer. Proceedings of the 3rd International Drying Symposium, ed. J. C. Ashworth (Wolverhampton, UK: Drying Research Ltd.,), Vol. 2, pp. 184-190 (1982).

Kucharski, J. and Kmiec A., Heat and mass transfer during coating of tablets in a spouted bed. Inzynieria Chemiczna I Procesowa, 1, 47 (1993).

Kucharski, J. and Kmiec A., Hydrodynamics, heat and mass transfer during coating of tablets in a spouted bed. Canadian Journal of Chemical Engineering, 61, 435-439 (1983).

Kucharski J., Heat transfer in a spouted bed granulator. Hungarian Journal of Industry and Chemistry, 17, 437 (1989).

Lan, X., Xu, C., Gao, J., and Al-Dahhan, M., Influence of solidphase wall boundary condition on CFD simulation of spouted beds, Chemical Engineering Science, 69, 419 (2012).

Liu, G.Q., Li, S.Q., Zhao, X.L., and Yao, Q., Experimental studies of particle flow dynamics in a two-dimensional spouted bed. Chemical Engineering Science, 63, 1131 (2008).

Lopez G., Erkiaga A., Amutio M., Alvarez J., Barbarias I., Bilbao J. and Olazar M., steam gasification of waste plastics in a conical spouted reactor. The 14th international conference on fluidization - from fundamentals to products (2013).

Lopez G., Olaza M., Aguado R., Bilbao J., Continuous pyrolysis of waste tyres in a conical spouted bed reactor. Fuel, 89, 1946 (2010).

Lun, C.K.K., Savage, S.B., Jeffrey, D.J., and Chepurniy, N., Kinetic theories for granular flow: inelastic particles in Couette flow and slightly inelastic particles in a general flow field. Journal of Fluid Mechanics, 140, 223 (1984).

Makibar J., Fernandez-Akarregi A.R., Alava I., Cueva F., Lopez G., Olazar M., Investigations on heat transfer and hydrodynamics under pyrolysis conditions of a pilot-plant draft tube conical spouted bed reactor. Chemical Engineering and Processing, 50, 790 (2011).

Moradi, S., Yeganeh, A., and Salimi, M., CFD-modeling of effects of draft tubes on operating condition in spouted beds. Applied Mathematical Modelling, 37, 1851 (2013).

Ogawa, S., Umemura, A., and Oshima, N., On the Equation of Fully Fluidized Granular Materials. Journal of applied mathematics and physics, 31, 483 (1980).

Olazar M., San Jos'e M. J., Aguirre G., and Bilbao J., Pyrolysis of sawdust in a conical spouted bed reactor. Yields and product composition. Ind. Eng. Chem. Res., 39, 1925 (2000).

Patil, D.J., Smit, J., Annaland, M.S., and Kuipers, J.A.M., Wallto-Bed Heat Transfer in Gas-Solid Bubbling Fluidized Beds. AIChE Journal, 52, 58 (2006).

Rosiane L. Cunha, Karen G. Maialle, Florencia C. Menegalli. Evaluation of the drying process in spouted bed and spout fluidized bed of xanthan gum: focus on product quality. Powder Technology, 234 (2000).

Schaeffer, D.G., Instability in the Evolution Equations Describing Incompressible Granular Flow. Journal of differential equations, 66, 19 (1987).

Setarehshenas, N., Hosseini, S.H., Nasr Esfahany, M., and Ahmadi, G., Impacts of solid-phase wall boundary condition on CFD simulation of conical spouted beds containing heavy zirconia particles. Journal of the Taiwan Institute of Chemical Engineers, 64, 146 (2016).

Shuyan, W., Zhenghua, H., Dan, S., Yikun, L., Lixin, W., and Shua, W., Hydrodynamic simulations of gas-solid spouted bed with a draft tube. Chemical Engineering Science, 65, 1322 (2010).

Sutkar, V.S., Deen, N.G., Mohan, B., Salikov, V., Heinrich, S., Antonyuk, S., and Kuipers, J.A.M., Numerical investigations of a pseudo-2D spout fluidized bed with draft plates using a scaled discrete particle model. Chemical Engineering Science, 104, 790 (2013a).

Sutkar, V.S., Deen, N.G., Patil, A.V., Salikov, V., Antonyuk, S., Heinrich, S., and Kuipers, J.A.M., CFD-DEM model for coupled heat and mass transfer in a spout fluidized bed with liquid injection. Chemical Engineering Journal, 288, 185 (2016).

Sutkar, V.S., van Hunsel, T.J.K., Deen, N.G., Salikov, V., Antonyuk, S., Heinrich, S., and Kuipers, J.A.M., Experimental investigations of a pseudo-2D spout fluidized bed with draft plates. Chemical Engineering Science, 102, 524 (2013b).

Swasdisevi, T., Tanthapanichakoon, W., Charinpanitkul , T., Kawaguchi, T., Tanaka, T., and Tsuji, Y., Prediction of gasparticle dynamics and heat transfer in a two-dimensional spouted bed, Advanced Powder Technology, 16, 275 (2005).

Szafran, R.G. and Kmiec, A., CFD Modeling of Heat and Mass Transfer in a Spouted Bed Dryer, Industrial Chemiacal Engineering Research, 43, 1113 (2004).

Zhao, X.-L., Li, S.-Q., Liu, G.-Q., Song, Q., and Yao, Q., Flow patterns of solids in a two dimensional spouted bed with draft plates: PIV measurement and DEM simulations. Powder Technology, 183, 79 (2008a).

Zhao, X.L., Li, S.Q., Liu, G.Q., Yao, Q., and Marshall, J.S., DEM simulation of the particle dynamics in two-dimensional spouted beds. Powder Technology, 184205 (2008b). 